\title{
Behind the Themes and Between the Lines
}

The saga of materials tells us all about materials but not of the people who make them. But people matter for they alone transform nature's artifacts to useful materials. And how does it feel to be a materials scientist or an engineer? The private frustrations, the public postures and feelings of personal satisfaction or effacement are all lost between the lines of scientific articles and patent descriptions.

Is it possible to explore what makes scientists pursue a certain line of reasoning?
How was a particular experiment or a material chosen and why were the others abandoned? How were the moments of discovery and invention encountered and how did failures fracture the road?

To look behind the scenes and to reveal the people who have helped move materials science along its course, this month's issue of MRS Bulletin introduces a new department called PROFILES \& PeRsPectives. This department presents interviews with researchers, developers, technologists, and other contributors who have a special insight into the development and status of the field of materials research because of their unique placement in the field's history.

Interviews were conducted by the Bulletin editorial staff and volunteers, and were held at the most accessible "home base" of those interviewed. We hope readers enjoy eavesdropping on these conversations.

ELIZABETH FLEISCHER, EDITOR bulletin@mrs.org

\section{SEND LETTERS TO THE EDITOR TO:}

Editor, MRS Bulletin, Materials Research Society, 506 Keystone Drive,

Warrendale, PA 15086-7573

Fax 724-779-8313 E-mail Bulletin@mrs.org

Letters must include your full name, institution, address, phone number, and e-mail if available.

\section{PHOENIX}

\section{Unleash the Power of X-ray Microanalysis}

Setting the standard in x-ray microanalysis, Phoenix, the most powerful system available offers the next generation of EDS...today. Phoenix delivers the ultimate in performance capabilities plus

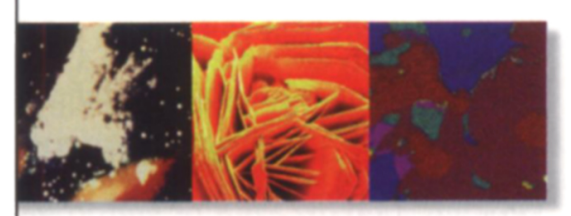
reliability, upgradability and flexibility. This user-friendly, easy-to-operate work station with 32-bit software is available for Windows ${ }^{\bullet}$ TT or Windows '98. Accelerate your performance with Phoenix...the most powerful tool in microanalysis!

- Power - true standardless, high quality quantification regardless of the matrix, plus the ability to achieve a high speed quantitative map in the same time as a gross map, along with a digital pulse processor.

- Simplicity - full quantitative results in seconds at the click of a mouse. Generate reports easily and import into other programs.

- Support - remote application and service support through REMAC.

To power-up your microanalysis capabilities, call EDAX today.

91 Mckee Drive

Mahwah, N 07430-9978

Tel. Office: 201-529-4880

Fax: 201-529-3156
Ringbaan Noord 103, P.0. Box 4144 5004 JC Tilburg. The Netherlands Tel. Office: $+31-13-5364000$ Fax: +31-13-5356279
13-37, Kohnan 2-chome, Minato-ku Tokyo 108, Japan Tel. Office: 81-3-3740-5172 Fax: 81-3-3740-5190

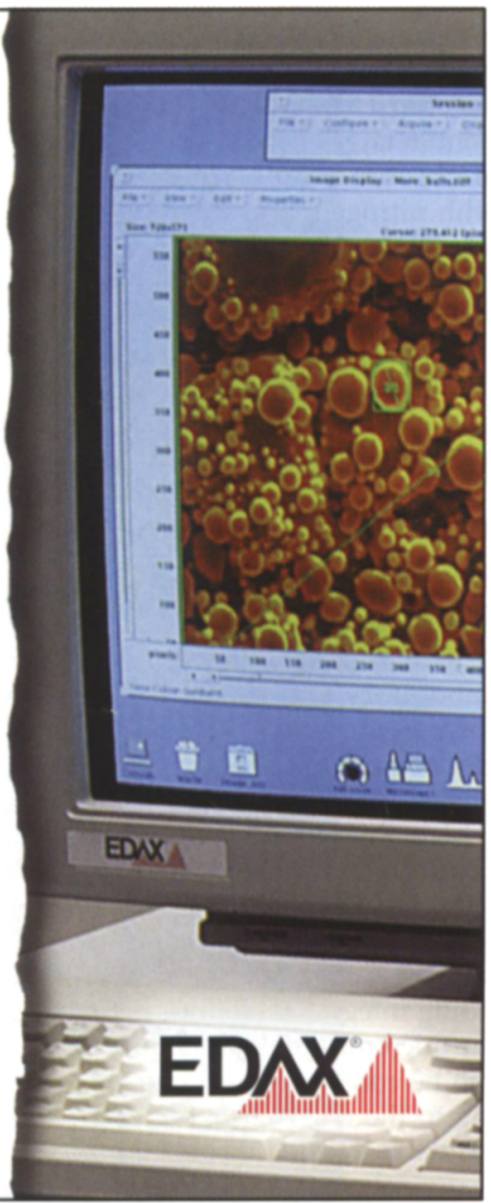

